\title{
Induced Hyperglycemia in Mice is Controlled Following the Microfluidic System- Assisted Transplantation of Stem Cells-derived Insulin- producing Cells Transduced with miRNA
}

\section{Adele Soltani}

Tarbiat Modares University Faculty of Medical Sciences

Masoud Soleimani

Tarbiat Modares University Faculty of Medical Sciences

Mohammad Adel Ghiass

Tarbiat Modares University Faculty of Medical Sciences

\section{Seyed Ehsan Enderami}

Mazandaran University of Medical Sciences

\section{Shahram Rabbani}

Tehran University of Medical Sciences

Arefeh Jafarian

Tehran University of Medical Sciences

Abdolamir Allameh ( $\square$ allameha@modares.ac.ir)

Tarbiat Modares University Faculty of Medical Sciences https://orcid.org/0000-0003-0757-9572

\section{Research}

Keywords: Anti-miR-7, IPCs, Diabetes, Encapsulation, Microfluidics, miR-375

Posted Date: September 18th, 2020

DOI: https://doi.org/10.21203/rs.3.rs-77365/v1

License: (a) (i) This work is licensed under a Creative Commons Attribution 4.0 International License. Read Full License 


\section{Abstract}

\section{Background}

Cell-based therapy is a promising approach for the treatment of type 1 diabetes mellitus. Identification of stem cells as progenitor stem cells with differentiation potential to Insulin-producing cells (IPCs) and their application is an emerging issue. Different strategies have been used to support the cell survival and their specific functions to control hyperglycemia condition. Novel technology systems using appropriate materials/fibres can improve the cell transplantation.

\section{Methods}

In the present study, glucose-sensitive insulin-producing cells (IPCs) were differentiated from adiposederived stem cells (ADSCs) transduced with miR-375 and anti-miR-7 to enhance the functions of the cells. The survival rate of the cells was also improved by using a microfluidic system prior to in vivo transplantation of the IPCs. The contribution of miR-375 with the anti-miR-7 in mature IPCs derived from ADSCs resulted in gaining the function of the cells as judged by insulin production

\section{Results}

After adopting a stable functional condition of the IPCs, the cells were used for in vivo grafting to diabetic mice which resulted in a substantial drop (5-folds) in blood glucose during four weeks of grafting. The pattern of blood glucose levels in the mice receiving fiber entrapped IPCs was similar to that of nondiabetic mice and blood glucose declined in animals treated with fiber-entrapped-IPCs. Blood insulin was elevated (2-folds) in diabetic mice received transplant of fiber-entrapped-IPCs carrying miR-375 and antimiR-7 after five weeks of transplantation when compared to the untreated diabetic mice. For the first time, this study showed that the two-component microfluidic system is useful for supporting the CollagenAlginate fiber-entrapped IPCs and the miRNAs-based cell therapy.

\section{Conclusions}

Overall data show that the IPCs encapsulation by the microfluidic system can support the cells in terms of morphology and biological function and their efficiency for controlling the hyperglycemia condition in diabetic mice.

\section{Background}

Type 1 diabetes involves the destruction of over $75 \%$ of pancreatic islet beta-cells mediated by autoimmune reactions, absolute insulin deficiency, and hyperglycemia [1]. The conventional treatment protocols do not definitively improve diabetes, but they do help to temporarily control blood sugar levels in a variety of mechanisms [2]. Transplantation of isolated islets of Langerhans from cadaveric donors could be a cure for diabetes [3]; however, this therapeutic strategy is limited by the shortage of organ donors, exhaustion of the transplanted cells and long-term side effects of immunosuppressive agents [4]. 
In recent years attention has been made on identification of stem cells and their application as a renewable source of cells to be differentiated into Insulin-producing cells (IPCs) [5, 6]. Adipose-derived stem cells (ADSCs) with high multiplication potency and immune-regulatory properties have attracted significant attention for the treatment of diabetes mellitus (DM) [7]. The ADSCs are known for their safety and efficacy compared to embryonic stem cells (ESCs) in both humans and animals, without posttransplant malignancy [8].

In general, the success of in vivo transplantation relies on various factors, among which the matrix and material used to transfer and support the cells and their function is the most important factor. In case of IPCs, the main concern for grafting is to preserve the morphology of the cells in form of cell clusters. Therefore it was assumed that the microfluidic system can protect the cell viability, morphology and functions [9].

Alginate hydrogel with calcium ion solution has been widely used as a scaffold for cell encapsulation using flow-focusing microfluidic device [10]. For example, Jun et al., (2013) have successfully showed that islet like clusters (ILCs) encapsulation with alginate was applied to immune protection of transplanted islets [11].

It has been suggested that specific miRNAs can also help in improvement of IPCs and their use in cell and molecular therapy. Certain miRNAs are known as important regulatory molecules in multiple processes, including the fate of beta-cells, cell proliferation, differentiation, survival, and apoptosis [12]. Also, several miRNAs are known to participate in beta-cells functions such as insulin expression and secretion, glucose metabolism [13].

Recently the miRNAs with positive and negative regulatory activities on the insulin and IPCs function and their implications in diabetes complications such as cardiomyopathy, nephropathy, and neuropathy has been reviewed [6]. It has been reported that, miR-375 is highly expressed in beta-cells and plays an important role in controlling insulin gene expression and secretion and compensatory beta-cells proliferation and differentiation [14]. It has also been reported that miR-375 plays a significant role in maintaining beta-cell mass and regular glucose homeostasis by preserving normal beta-cells and betacell mass proportion [15]. It has been reported that by targeting myotrophin (Mtpn), miR-375 can reduce insulin exocytosis and secretion [16]. This molecule is also responsible for repression of 3phosphoinositide-dependent protein kinase-1 ( $P d k 1$ ) [17] that might affect the downstream insulin signalling [18]. mir-7 is another miRNA that has been involved in the control of endocrine pancreas development [12]. Wang and his group showed that differentiation of beta-cells and pancreas development is affected by mir-7 through targeting paired box6 ( mTOR pathways [19]. It has also been reported that the miR-7 can inhibit insulin granule secretion by targeting Myrip (myosin VIIA and Rab interacting protein) [20] as a partner of small GTPase Rab27 and Pax6 is a transcriptional factor regulating insulin biosynthesis and secretion [21].

Based on these reports, it appears that some miRNAs is considered as a useful approach for differentiation of IPCs [22]. The present study was designed to figure study the impact of up-regulation of 
miR-375 and down-regulation of miR-7 during the differentiation of IPCs from the ADSCs and their response to different glucose concentrations. The experiment was pursued by encapsulation of the IPCs using Collagen-Alginate microfiber which mimics the native microenvironment of islets in the pancreas. The microfibers were then transplanted to a mouse model of diabetes, to see if the microfluidic system can help to improve the functional beta-cells as a therapeutic option for diabetic condition.

\section{Materials And Methods}

\subsection{Isolation and Characterization of ADSCs}

This study was approved by the Animal Ethical Committee of Tarbiat Modares University, Tehran, Iran (IR.TMU.REC.1396.692).

Adipose tissue was obtained from the abdominal cavity of Balb/c mice and digested for $45 \mathrm{~min}$ at $37^{\circ} \mathrm{C}$ in PBS, pH=7.2 (Gibco, Germany), containing 2\% BSA (Sigma-Aldrich, USA), and 0.2\% collagenase type-I (Gibco, Germany). The isolated ADSCs at a density of $2 \times 10^{5} \mathrm{cells} / \mathrm{cm}^{2}$ were seeded into $\mathrm{T}_{25}$ culture flasks and incubated at $37^{\circ} \mathrm{C}, 5 \% \mathrm{CO}_{2}$.

The ADSCs at passage three with appropriate monoclonal antibodies labelled with FITC or PE (BD Biosciences, USA) were analysed using fluorescence-activated cell sorting on a FACS Caliber (BectonDickinson, FAC scan, San Jose, CA, USA).

To confirm the adipogenic and osteoblastic differentiation potential of ADSCs, the cells were subjected to differentiation process and then, the cell were stained with Oil-Red-O and alizarin red (Sigma-Aldrich, USA) respectively and examined under phase-contrast microscopy (Olympus, Japan). The cells were also examined during osteogenesis for alkaline phosphatase activity using BCIP/NBT reagent (Becton Dickinson, Bioscience, UK) for 10-15 min [23].

\subsection{Transduction of ADSCs with miR-375 and anti-miR-7 genes}

The psPAX2 (containing gag and pol genes) and pMD2.G (containing VSV-G gene), as lentiviral packaging plasmids, mmu-mir-375 (containing the CMV and SV40 promoters (\#abm. mm10408, Abm good. Canada), mmu-miR-7-inhibitor vector (\#abm. MIM03178, Abm good. Canada) and pLenti-III-mirGFP-Blank (\#abm. m001, Abm good. Canada) were used for the co-transfection of HEK-293T cells. Plasmids then purified by midi Plus kit (MN, Germany) according to the instruction provided by the manufacturer.

HEK-293T cells (purchased from Stem Cell Technology Research Center, Tehran, Iran) were seeded in 6 cm Petri dishes with DMEM+10\% FBS. The lentivirus carrying miR-375 and anti-miR-7 were propagated from the co-transfection in the HEK-293T cell line using the lipofectamin 2000 transfection reagent (Invitrogen, USA). The titer of the concentrated viral particles was determined using flowcytometry. To determine the titer of the GFP-expressing virus, a serial dilution was prepared and added to HEK-293T 
cells in culture. The transducing unit (TU/ml) of the GFP-expressing cells was determined for each dilution after 48 hours. A well containing HEK-293T cell without the viral dilution was also taken and considered as the negative control.

The ADSCs at passage three with $70-80 \%$ confluency were considered for lentivirus transduction. The experimental groups were designated as described below:

Group-1: The ADSCs transduced with mmu-miR-375 lentiviruses carrying GFP (ADSCs miR-375), Group-2: The cells transduced with mmu-miR-7-off lentiviruses carrying GFP (ADSCs anti-miR-7), Group-3: The cells infected with both miRNAs (ADSCs miR-375+anti-miR-7), Group 4: The cells infected with pLentiempty lentiviruses carrying GFP (ADSCs null), Group 5: The control group, only ADSCs (no transduction).

The multiplicity of infection (MOI) of 30 was considered appropriate for all the experiments. The cells were cultured for one week in fresh complete serum-free medium containing DMEM supplemented with BSA (15\%) and $2 \mu \mathrm{g} / \mathrm{ml}$ puromycin (Sigma-Aldrich, USA).

\subsection{Expression of miR-375, miR-7, and its gene targets in the transduced cells}

The transduction efficiency was examined by GFP expression in the transduced cells under a fluorescence microscope. For determined the miR-375, miR-7 expression, total RNA was extracted from the cells using Trizol reagent (Invitrogen, USA) as instructed by the manufacturer, on day 4 of transduction. In following the experiment, total cellular RNA was isolated from transduced and control cells on days 7, 14, and 21 post-infection using Trizol for determined the pancreatic specific genes. The quality and quantity of the extracted RNA samples was checked on a Nanodrop (Thermofisher, USA). cDNA was synthetized from each RNA sample (2ng) using a cDNA synthesis kit according to the instructions given by the company (iNtRON Biotechnology, Korea). The expression of genes was determined using quantitative real-time PCR (QRT-PCR) using SYBR green kit (Takara, Korea). The assay was performed in triplicate in a reaction mixture on a real time PCR system (Applied Biosystems, ABI7500). PCR reaction was performed with mmu-miR-375, mmu-miR-7 primers, and U6 small nuclear RNA endogenous control primers. The qRT-PCR cycling condition was as follows: $95 \mathrm{C}$ for $10 \mathrm{~min}$, followed by 40 cycles (each cycle for $15 \mathrm{sec}$ at $95 \mathrm{C}$ and $1 \mathrm{~min}$ at $60 \mathrm{C}$ ). The primers used in this experiment are as listed in Additional file 1: Table S1. The relative quantification $(\Delta \Delta \mathrm{Ct})$ method was applied to calculate the data. Using this assay the gene transcripts of IPCs were compared with that of a mouse pancreatic betacell line (MIN-6, purchased from Iranian Biological Resource Center, Tehran, Iran).

\subsection{Visualization of the spheroid IPCs and immunofluorescence staining}

Formation of the spheroid IPCs obtained on day 21 of differentiation from ADSCs was evaluated by dithizone (DTZ) staining [24]. The cells were further characterized by showing specific protein localization by ICC technique [25]. The IPCs were treated with primary antibodies against Insulin (\#ab7760, Abcam, Cambridge, MA, UK), Glucagon (\#ab10988, Abcam), Pdx1 (\#ab84987, Abcam), and Neurogenin3 (\#ab87108, Abcam). The FITC-coupled goat anti-mouse IgG (\#AF8032, Razi Biotech, Iran) and Texas Red- 
labelled goat anti-mouse IgG (\#ab175473) were used as secondary antibody. Besides, samples were processed without primary antibody and considered as negative control. All the ICC assays were performed in triplicate. Wherever indicated, the nuclei of the cells were stained with DAPI $(0.1 \mu \mathrm{g} / \mathrm{ml})$.

\subsection{Estimation of insulin and C-peptide secretion by IPCs}

Insulin and C-peptide levels secreted by the IPCs were measured using an ultrasensitive mouse ELISA kit (\#Mecodia, Uppsala, Sweden, and \# Alpco, Salem, USA respectively). The assays were carried out according to the procedure described by the manufacturer's instruction. Glucose-stimulated insulin release was assayed in differentiated cells after the cells were incubated for 2 hours in freshly prepared Krebs-Ringer bicarbonate buffer (KRB) (Sigma-Aldrich, USA) without glucose. Then the cells were incubated for 2 hours in KRB containing $0.5 \mathrm{mmol}$ IBMX (lisobutyl- 3-methylxanthine (Sigma-Aldrich, USA) and different glucose concentrations $(5,10,15,20,25$, and $30 \mathrm{mmol})$. In case of insulin and C-peptide assays in the cells, the cells were first washed for three times with PBS, extracted in $0.2 \mathrm{ml}$ acid alcohol ( $10 \%$ glacial acetic acid in absolute ethanol) at $4^{\circ} \mathrm{C}$ overnight, and sonicated briefly before centrifugation at $3500 \mathrm{~g}$ for $15 \mathrm{~min}$ at $4^{\circ} \mathrm{C}$. Total protein concentration was determined by BCA protein assay system and $50 \mu \mathrm{g}$ of protein was used for detection of intracellular insulin and C-peptide in each well of ELISA kit. Absorption was recorded at $450 \mathrm{~nm}$ and all the assays were carried out in triplicate.

\subsection{Assembly of microfluidic device and Collagen-Alginate micro-fiber}

In this experiment, microfluidic device was fabricated using standard soft lithography methods [26, 27]. Cylindrical and coaxial-flow channels were prepared by aligning and bonding Poly dimethyl siloxane (PDMS) channels by oxygen plasma treatment (Harrick Scientific, Ossining, NY) to produce CollagenAlginate fibers. The diameters of the cylindrical channel at the inlet, tapered junction, and outlet were 400, 200 , and $600 \mu \mathrm{m}$, respectively. In this device, solutions were supplied from the inlets: a sample fluid (cells suspended in Collagen-Alginate solution), and a sheath fluid (3\% (w/v) calcium chloride, dissolved in deionized water). Sodium alginate (Sigma-Aldrich) was prepared in culture medium and collagen by mixing collagen solution and alginate and gently pipetting with cell pellets at a concentration of $1.5 \times 10^{6}$ cells $/ \mathrm{ml}$. The flow rate of each fluid was adjusted to $100 \mu \mathrm{l} / \mathrm{min}$ with the help of a syringe pump and the sheath flow rate was about $1 \mathrm{ml} / \mathrm{min}$. The extruded fibers were collected in a Petri dish containing $\mathrm{CaCl}_{2}$ and incubated in culture medium at $37^{\circ} \mathrm{C}$ for $45 \mathrm{~min}$.

\subsection{Characterization of the microfiber}

Live/dead staining: The viability of encapsulated IPCs was evaluated at 1 and 7 days after encapsulation using mixture of acridine orange $\left(100 \mu \mathrm{g} \mathrm{mL}^{-1}\right)$ and ethidium bromide $\left(100 \mu \mathrm{g} \mathrm{mL}^{-1}\right)$ and viewed using a fluorescence microscope. Acridine orange penetrates into cells and stains the DNA of live cells green fluorescence using blue filter, whereas ethidium bromide only enters dead cell membranes, stains the DNA of dead cells using green filter and generates a red fluorescence. Two images taken from the same field were merged by Photoshop8 CS software. 
Cytotoxicity assessment: Cytotoxicity of the Collagen-Alginate was assessed using 3-(4, 5dimethylthiazol-2-yl)-2, 5-diphenyltetrazolium bromide (MTT) assay. The differentiated encapsulated cells were soaked in DMEM supplemented with 5\% FBS. The cell proliferation was evaluated during 14 days in Collagen-Alginate fiber. Briefly, culture medium was removed and replaced with $20 \mu \mathrm{l}$ MTT $(0.5 \mathrm{mg} / \mathrm{ml})$ (Sigma) was added to each well and plates were incubated at $37^{\circ} \mathrm{C}$ in dark. The assay was carried out in triplicate, and the results are presented as mean \pm SD.

Microstructural of fiber (SEM): The surface of the freeze-dried fibers was examined using SEM (Philips XL30, Amsterdam, Netherlands). The porosity of fibers was measured using ImageJ software.

Fourier Transform Infrared Spectroscopy (FT-IR): The chemical structure of the synthesized hydrogels was investigated by using FT-IR spectroscopy (FT-IR 8400S, Shimadzu, Japan) in the wavenumber of $400-4000 \mathrm{~cm}^{-1}$.

Swelling property was examined by doing the cross-linked composite porous fibers.

The fibers were weighed every 50 min and then immersed in excess of swelling medium $(\mathrm{pH}=7.4)$ at $37 \circ \mathrm{C}$ until they reach the equilibriums. At various time intervals, the hydrogel was removed from the solution and weighed after blotting the excess water using blotting paper. The weight of the swollen fibers was recorded every 50 min until they reach equilibrium state. Data presented in this paper are mean values of triplicate measurements. The percentage swelling of fibers was calculated according to the following equation: $\mathrm{Q}=(\mathrm{Ms}-\mathrm{Md}) / \mathrm{Md}$. Where, $\mathrm{Q}$ is the swelling ratio, $\mathrm{Ms}$ is the mass in the swollen state and $\mathrm{Md}$ is the mass in the dried state.

\subsection{In vivo experiment}

This experiment was carried out on male BALB/c mice. The mice were 8-10 weeks-old weighing $30 \pm 5 \mathrm{~g}$. Animals were housed in standard cages, with food and water ad libitum, under controlled temperature condition $\left(23 \pm 2^{\circ} \mathrm{C}\right)$. The experimental groups are as follows; Group-1: Diabetic mouse received IPCs $(n=5)$. Group-2: Diabetic mouse received MSCs $(n=5)$. Group-3: Non-diabetic mice I $(n=5)$. Group-4: diabetic mice as Control $(n=5)$.

Wherever indicated Type1 diabetes was induced in mice by administration of streptozotocin (STZ) treatments. Each mice received intra peritoneal (I.P) four consecutive injections of STZ $(80 \mathrm{mg} / \mathrm{Kg}$ dissolved in citrate buffer, $\mathrm{pH}=4.5$ ). Blood glucose level (non-fast) was readily monitored using a portable glucometer on blood samples collected from the tail vein (Accu-CHEK, Roche). Blood glucose was measured at different time intervals and considered as an index for hyperglycemia (diabetes). Blood glucose above $17 \mathrm{mmol} / \mathrm{I}$ was considered as abnormal which was achieved 5 days after the STZ administration. The animals were selected for transplantation received approximately $1.5 \times 10^{6}$ differentiated and non-differentiated cells encapsulated by the Collagen-Alginate fibers. Each mouse received subcutaneous implantation of fiber-entrapped cells on the back in the anaesthetized status using $50 \mathrm{mg} / \mathrm{kg}$ ketamine and $5 \mathrm{mg} / \mathrm{kg}$ xylazine. 
The functional efficacy of the transplant was evaluated after four weeks as shown by glucose tolerance test (GTT). Change in blood glucose in fasting mice was monitored for 6-10 hours at different time intervals $(20,40,60,90$ and $120 \mathrm{~min})$ following treatment with $2 \mathrm{~g}$ glucose/ $\mathrm{kg}$ body weight injected I.P. After 5 weeks of post transplantation (at the end of the treatment period before sacrificing), animals were anesthetized with an I.P. injection of ketamine $(70 \mathrm{mg} / \mathrm{kg})$ and xylazine $(10 \mathrm{mg} / \mathrm{kg})$ and $2 \mathrm{ml}$ of blood sample was collected by heart puncher and used to measure insulin level.

\subsection{Statistical analysis}

The statistical analysis was performed using One-way ANOVA and Bonferroni's post hoc test by Graph pad Prism5 software (GraphPad Software Inc., La Jolla, CA). The results are presented as mean $\pm S D$ and P-value less than 0.05 was considered statistically significant.

\section{Results}

\subsection{Characterization of the ADSCs}

The results of flowcytometry analysis of surface markers of the ADSCs isolated from the adipose tissues showed that the cells are positive for CD73 (92.1\%), CD90 (90.7\%), CD44 (89.3\%) and CD105 (83.6\%); Whereas the cells were negative for CD $45(0.14 \%)$ and CD34 $(0.43 \%)$ markers. The ADSCs were further characterized after they were induced for osteogenic and adipogenic differentiation of ADSCs. Following differentiation, on day 21, the osteoblasts were identified by their calcium deposits using Alizarin Red S stain. Accordingly, alkaline phosphatase activity was detected in the cells using BCIP/NBT (Becton Dickinson, Bioscience) as a substrate. In the case of adipogenic differentiation, the cells obtained on day 14, appeared with oil droplets stained with Oil-Red-O (Additional file 2: Fig S1).

\subsection{The impact of miRNAs transduction on ADSCs differentiation into IPCs}

ADSCs were transduced with lentiviral vectors with an efficiency of about $75 \%$ as determined by flowcytometry analysis and fluorescent microscopy (Fig.1 a\&b).

The expression of miR-375 was sharply increased (70-80 folds; $\mathrm{P}<0.05)$ in ADSCs following transduction with a lentiviral vector carrying this gene as compared to cells transfected with miRNA backbone (ADSCs null as control). The expression of miR-7 in ADSCs received anti-miR-7 was dropped by $4-5$ folds $(P<0.05)$, as compared to ADSCs null and ADSCs control (Fig.1c\&d).

The expression of Mtpn as the target of miR-375 was found to be inhibited in cells received miR-375 or miR-375 along with anti-miR-7. During the three weeks experiment, a noticeable decrease was observed in the gene expression after 7 days. The gene expression was further decreased by $30 \%(P<0.001)$ in cells collected on day 14, as compared to the control group. In contrast, expression of Myrip specific mRNA as a miR-7 target was substantially increased ( 40 folds) in cells treated with anti-miR-7 or the anti-miR7+miR-375 (Fig.1e\&f). 
Following transduction of miR-375 and anti-miR-7 lentiviruses into the ADSCs, after four days of infection, the adherent spindle-shaped cells started to form round-shape structures by assembling together. Such structures were gradually enlarged during two weeks of transduction in ADSCs carrying miR-375 or miR-375+anti-miR-7. Ultimately the larger structures formed were converted into cluster of IPCs; whereas, under similar conditions, stem cells carrying anti-miR-7 failed to form such structures. On day 21, the ADSCs expressing miR-375 and miR-375+anti-miR-7 were positively stained with DTZ as the indicator of the accumulation of zinc ions present in insulin molecules was stained red. The cells carrying anti-miR-7 alone were negatively stained with the DTZ (Fig.2).

\subsection{Expression of pancreatic-specific genes in transduced cells}

Time-course studies showed that the expression of the pancreatic transcription factors, namely, $P d x 1$, Neurog3 were significantly increased in ADSCs, received miR-375 or miR-375+ anti-miR-7. Likewise, there was a significant induction in expression of endocrine-related marker genes, including Ins1, Ins2, Gcg, and

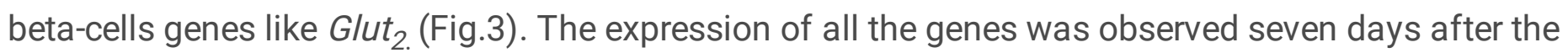
transduction, and the expression reached to maximum levels on day 14 after induction, after which the levels were gradually declined in ADSCs received miR-375 or miR-375+anti-miR-7. In contrast, the expression of the above-mentioned genes was unaffected in cells transduced with anti-miR-7 assuming that the miR-7 was blocked.

\subsection{Localization of pancreatic-specific markers in IPCs (ICC data)}

Comparison of immune-staining scoring of Insulin, $\mathrm{Pdx} 1, \mathrm{Ngn3}$, and glucagon in the cells transduced with miR-375 and miR-375+anti-miR-7 on day 21 of transduction, showed that the accumulation of the markers was relatively lower in cells transduced with miR-375 compared to miR-375+anti-miR-7 (Fig.4a).

\subsection{Assessment of functional activities of differentiated IPCs}

In this experiment, the cells bearing miR-375 lentivirus did not show response to various glucose concentrations ( 5 to $30 \mathrm{mmol}$ ) in terms of secretary insulin and C-peptide levels. However, the levels of intracellular insulin and C-peptide were significantly elevated in insulin-producing cells that carry miR-375. Also, the levels of secretary and intracellular insulin and C-peptide were significantly elevated in differentiated IPCs mediated by miR-375 over-expression and then miR-7 down-regulation (ADSCs miR$375+a n t i-m i R-7)$ group by different concentrations of glucose from 5 to $30 \mathrm{mmol}$ (Fig.4b, c, d \&e).

\subsection{Characterization of IPCs encapsulated with microfibers}

The microfluidic chip and its round micro-channels with dimensions are as shown in figure 5 . The produced fibers were approximately $200 \mu \mathrm{m}$ in diameter, build based on the cluster size of IPCs which were approximately 80 to $180 \mu \mathrm{m}$ in size. Higher magnification images taken by SEM revealed a rough and porous surface on the fiber preparation and the fibers porosity was calculated about $44.8 \%$. 
The FTIR spectra of the fibers showed two typical peaks of Collagen-Alginate, asymmetric tensile vibration at $1637 \mathrm{~cm}-1$ and another symmetric tensile vibration at $1412 \mathrm{~cm}-1$. Both the characteristic peaks move to $1600 \mathrm{~cm}-1$ and $1427 \mathrm{~cm}-1$, respectively, which is related to the cross-linking of carboxyl groups (COO) with the $\mathrm{CaCl}_{2}$ agent. On the other hand, absence of a clear peak in the range of $2800 \mathrm{~cm}-1$ to $3000 \mathrm{~cm}-1$, related to $-\mathrm{CH}$ vibration could be assigned to the proper interaction of alginate with collagen and the uniform alloy formation of the two.

The swelling behaviour data for the fiber cell-free constructs are as shown in Fig.5i, showed a rapid swelling of the fibers which occurred during the early incubation of $100 \mathrm{~min}$, which after $150 \mathrm{~min}$; the swelling tendency was stable for all the samples.

The fluorescence images were taken seven days after in vitro cultivation by using a live/dead assay reagent. It was found that alginate-collagen fiber entrapped cells has significantly more number of cells count on day seven compare to on day one thereby the collagen-alginate does not show inhibiting effect on cells proliferation. The viability of the fiber-entrapped IPCs was significantly increased as compared to that estimated in fiber-free IPCs (control group) on day three, which continued steadily for up to 14 days, indicating the support of the fibers for cell growth promotion and proliferation (Fig.6).

\subsection{The impact of the fiber-encapsulated IPCs transplantation on diabetic mice}

Blood glucose level in untreated (normal) mice was $4.213 \pm 0.33 \mathrm{mmol} / \mathrm{l}$, which was sharply increased to $23.9 \pm 0.45 \mathrm{mmol} / \mathrm{l}$ (5-fold) in the diabetic group. After the characterization of the fiber, the fibers entrapped IPCs were transplanted intra-dermally to 5 diabetic mice.

After four weeks, there was a significant decrease (mean $=11.027 \pm 0.88 \mathrm{mmol} / \mathrm{l}, \mathrm{p}<0.0001$ ) in blood glucose when compared to the control group of mice, which were transplanted with fiber entrapped undifferentiated ADSCs $(22.9 \pm 0.97 \mathrm{mmol} / \mathrm{l}, \mathrm{p}<0.0001)$. Moreover, four weeks after transplantation, the GTT data showed that the pattern of blood glucose levels in the mice receiving fiber entrapped IPCs was similar to that of non-diabetic mice and increased fasting blood glucose (FBG) which was initially raised, was lowered to $13.8 \pm 2.2$ and $6.47 \pm 0.39(p<0.0001)$ in mice treated with fiber entrapped IPCs and nondiabetic group respectively. Under this condition, insulin level was significantly elevated $(266.7 \pm 39.11 \mathrm{pg} / \mathrm{ml}), 5$ weeks after transplantation to mice as compared to diabetic group with blood insulin level of $162 \pm 19.5 \mathrm{pg} / \mathrm{ml}$ (Fig.7).

\section{Discussion}

In the present study, a microfluidic system was designed and applied to improve the survival rate of the functional IPCs differentiated from ADSCs. For this purpose, the ADSCs were used as progenitor stem cells knowing that these cells are an excellent source for the generation of IPCs, which represent a promising cell-based therapy in regenerative medicine and autoimmune diseases [28]. During the differentiation process the cells were fortified with regulatory miRNAs which presumably target insulinrelated genes. The study was continued with encapsulation of the IPCs using engineered microfiber 
microfluidic applicable for transplantation and grafting to the host. The data presented here show that during the ADSC differentiation, there were morphological changes together with the increased levels of insulin. The differentiation-dependent changed in morphological features of the ADSCs transduced with miR-375 and anti-miR-7, was more apparent. Significant morphological changes observed after four days of miR-375 and anti-miR-7 transduction were due to the conversion of spindle-shaped adherent stem cells into round-shape structures after gathering into clusters of IPCs. This data further support the influence of miR-375 in proliferation, differentiation, and regulation of insulin expression in beta-cells. In this line, evidences suggest that a moderate reduction $(25 \%)$ in beta cell mass is unlikely to cause insulin deficiency and diabetes $[14,15,29]$. Moreover, formation of the IPCs during the differentiation process was confirmed by showing the over-expression of pancreatic-specific genes, namely, Pdx1, Neurog3, Ins1, Ins2, Gcg, and Glut 2 . This was further confirmed by showing the overexpression of target genes in the IPCs transduced with miR-375 or miR-375+anti-miR-7. The expression of the genes was noticed seven days after the transduction which reached maximum levels on day 14 after induction. A decline in the expression of insulin-related genes occurred after 14 days, which is probably due to a decline in the cell population. The impact of the up-regulation of miR-375 and down-regulation of miR-7 in ADSCs was indicated by ICC. This was further supported by showing that nuclear localization of Pdx 1 , Neurog3, and cytoplasmic localization of Insulin and Glucagon in differentiated IPCs on day 21 in ADSCs miR375 +anti-miR7 groups. This data implies that targeting certain pancreatic-specific genes by miR-375, the differentiation process of the ADSCs into IPCs in the absence of cytokines and stimulatory growth factors can be increased. Several transcription factors such as $P d x 1$, Neurog3, Sox9, and Pax6 are known to control pancreas development and play important role in beta-cell mass, likewise, miR-375 and miR-7 by targeting $P d x 1$ and $P a x 6$ genes are important in pancreatic development and beta cell function $[25,30$, 31].

As a consequence of transduction of miR-375 and, or anti-miR-7 via lentivirus infection, there was a significant increase in the rate of insulin accumulation in the cells and insulin secretion into the culture media. Under such circumstances by augmentation of glucose concentration in IPCs, the levels of secretary and intracellular insulin and C-peptide were also significantly increased. The data in Fig.1 clearly attest to the contribution of miR-375 over-expression and then miR-7 down-regulation in regulation of ADSC differentiation. Nevertheless, accumulation of intracellular insulin in IPCs with little secretion in cells transfected with miR-375 lentivirus alone could link to decreased Mtpn expression.

Based on the in vitro assays, it appears that the up-regulation of miR-375 plays an important role in the aggregation of IPCs cluster and the regulation of insulin synthesis by these cells during their differentiation from ADSCs. As a consequence of overexpression of miR-375 in the IPCs, and significant decrease in Mtpn expression (the protein target of miR-375 which involves in vesicle exocytosis from beta-cells), could be responsible for impairment in Glucose-stimulated insulin secretion (GSIS) in ADSCs. The insulin secretion is believed to be related to beta-cell maturation. Also, overexpression of miR-375 by targeting Mtpn could result in decreased insulin exocytosis and secretion [17]. 
Evidences also show that inhibition of miR-7 in differentiated IPCs is linked to Pax6 mediated increase in GSIS and insulin transcription genes known as genes 1 and 2. Also, a significant increase in Myrip expression, as a consequence of mir-7 suppression, may suggest that increased Myrip is can lead to downstream changes, such as the formation tripartite complex with Rab27a and myosin and insulin granule transportation and secretion [32,33].

The use of fiber for graft transplantation in diabetic mice is implicated in the improvement of insulin release and improvement of glucose levels in vivo. The advantages of using encapsulation material using collagen-alginate composite (CAC) for uniform-size islet spheroids for in vivo transplantation to diabetic animals has been elucidated. The application of CAC using microfluidic device for islet transplantation with emphasize on immune-protection of the transplanted islet further support the use of CAC [11].

Based on these findings, the Collagen-Alginate packed matured IPCs given subcutaneously to STZ induced diabetic mice could substantially modulate blood glucose level by lowering its level to $11.02 \pm 0.88 \mathrm{mmol} / \mathrm{l}$ after four weeks, which was abnormally elevated in diabetic mice. In contrast, there was no sign of blood glucose depletion in mice transplanted with undifferentiated ADSCs alone (control). The glucose lowering ability of the IPC transplantation using collagen-alginate system was associated with increased level of blood insulin in diabetic mice when compared to the control groups. Among the factors contributing to the efficiency of in vivo transplantation was the number of cells transplanted. It is assumed that the adequate number of cells and IPCs which can enhance the efficiency of transplantation is approximately, $1.5 \times 10^{6}$. The number of the cells depends on the rate of the ADSCs conversion to IPCs, which is considered important for the efficiency of the graft [9].

According to Silva et al., encapsulation using alginate hydrogels is a strategy being explored as a potential cellular therapy for type-I diabetes conditions without the need for immunosuppression. Encapsulated allogeneic/xenogeneic transplantation of islets shows promise in the in vivo experiment with blood glucose levels being normalized for extended periods [34]. Perhaps, the encapsulation of the cells using the composite of alginate and collagen mimics the micro-invertebrates of functional beta-cells in the pancreas. The alginate hydrogel membrane could facilitate insulin secretion; in addition, fibers by preventing the penetration of immune cells can temporarily protect the cells from cellular immunological challenges. This procedure could facilitate exocrine secretion of insulin as well as allow the penetration of oxygen, nutrients, and glucose inside the microfiber [11,35]. Therefore, the collagen content of the microfiber is also considered as an important factor in supporting the survival and optimal functions of the IPCs. This finding is also supported by studies showing that macro-encapsulation of pig islet cells supports the graft survival and function by increasing oxygenation and neo-angiogenesis [36, 37].

In this experiment, the swelling ratio and retention properties are critical indicators of body fluids and for the transfer of cell nutrients and metabolites inside the scaffold. These properties have confirmed the stabilization of the shape and size of the scaffolds during in vitro cell culture and in vivo implantation 
$[38,39]$.The advantages of using encapsulation material using collagen-alginate composite for uniformsize islet spheroids for in vivo transplantation to diabetic animals has been elucidated [40].

\section{Conclusion}

In conclusion, the results presented here clearly show that miR-375 and, or anti-miR-7 play important roles in differentiation of ADSCs into mature and functional IPCs. The IPCs responsive to glucose challenge did not elicited following the up-regulation of miR-375 alone, whereas, suppression of miR-7 following over expression of miR-375 caused significant changes in glucose response and insulin secretion. In vivo experiment showed that the use of advanced cell therapy systems with Collagen-Alginate fiber-entrapped IPCs is associated with supporting the IPC survival and better functions to control hyperglycaemic condition, suggesting that the encapsulation of IPCs is promising for successful allograft transplantation.

\section{Abbreviations}

ADSCs: Mesenchymal stem cells

DM: Diabetes mellitus

DTZ: Dithizone

GTT: Glucose tolerance test

GSIS: Glucose-stimulated insulin secretion

IBMX: lisobutyl- 3-methylxanthine

ILCs: Islet-like clusters

I.P: Intra peritoneal

IPCs: Insulin-producing cells

FBG: Fasting blood glucose

miRNAs: micro (mi)-RNAs

3'-UTR: 3' Untranslated region

GAPDH: Glyceraldehyde-3-phosphate dehydrogenase

Mtpn: Myotrophin

MTT: 3-(4, 5-dimethylthiazole-2-yl)-2, 5- diphenyltetrazolium bromide 
PDK1: 3-phosphoinositide-dependent protein kinase-1

PDMS: Poly dimethyl siloxane

Pax6: Paired box 6

PE: Phycoerythrin

qRT-PCR: Quantitative real-time PCR

RT: Room temperature

SEM: Scanning electron microscopy

STZ: Streptozotocin

\section{Declarations}

\section{Acknowledgements}

The authors wish to thank Ms. A. Afshar Naderi for her helpful advice on technical issues examined in this study.

\section{Funding}

This study has been supported by a grant from INSF: Iranian National Science Foundation [Grant number 97012980].

\section{Availability of data and materials}

All data generated or analysed during this study are included in this published article [and its supplementary information files].

\section{Authors' contributions}

AA and AJ are responsible for the conceptualization and project administration. AS, SR and, MS are responsible for the methodology. AS and MS are responsible for the validation. AS and MAG are responsible for the investigation. AJ is responsible for the resources. AS and AA are responsible for the writing and review and editing. SEE and SR are responsible for the visualization and analysis. All authors read and approved the final manuscript.

\section{Ethics approval and consent to participate}

All experimental procedures were conducted in accordance with international guidelines for animal studies and approved by the ethical committee for animal research, Tarbiat Modares University, Tehran (IR.TMU.REC.1396.692). 


\section{Consent for publication}

Not applicable

\section{Competing interests}

The authors declare that they have no competing interests.

\section{References}

1. care. Standards of medical care in diabetes-2015: summary of revisions. Am Diabetes Assoc. 2016;39 Suppl 1:S4-S5.

2. Bergenstal RM, Tamborlane WV, Ahmann A, Buse JB, Dailey G, Davis SN, Joyce C, Peoples T, Perkins BA, Welsh JB, Willi SM. Effectiveness of sensor-augmented insulin-pump therapy in type 1 diabetes. N Engl J Med. 2010;363:311-20.

3. Shapiro AJ, Lakey JR, Ryan EA, Korbutt GS, Toth E, Warnock GL , Kneteman NM, Rajotte RV. Islet transplantation in seven patients with type 1 diabetes mellitus using a glucocorticoid-free immunosuppressive regimen. N Engl J Med. 2000;343:230-8.

4. Chen L-B, Jiang X-B, Yang L. Differentiation of rat marrow mesenchymal stem cells into pancreatic islet beta-cells. World J Gastroenterol. 2004;10:3016.

5. Pan G, Mu Y, Hou L, Liu J. Examining the therapeutic potential of various stem cell sources for differentiation into insulin-producing cells to treat diabetes. Ann Endocrinol. 2019;80: 47-53.

6. Soltani A, Jafarian A, Allameh A. The Predominant microRNAs in $\beta$-cell Clusters for Insulin Regulation and Diabetic Control. Curr Drug Targets. 2020, 21:722-34.

7. Strauer BE, Kornowski R. Stem cell therapy in perspective. Circulation. 2003;107:929-34.

8. Zang L, Hao H, Liu J, Li Y, Han W, Mu Y. Mesenchymal stem cell therapy in type 2 diabetes mellitus. Diabetol Metab Syndr. 2017;9:36.

9. Vaithilingam V, Evans MD, Lewy DM, Bean PA, Bal S, Tuch BE. Co-encapsulation and cotransplantation of mesenchymal stem cells reduces pericapsular fibrosis and improves encapsulated islet survival and function when allografted. Sci Rep. 2017;7:1-13.

10. Sakata N, Obenaus A, Chan NK, Mace J, Chinnock R, Hathout E. Factors affecting islet graft embolization in the liver of diabetic mice. Islets. 2009;1:26-33.

11. Jun Y, Kim MJ, Hwang YH, Jeon EA, Kang AR, Lee S-H, Lee DY. Microfluidics-generated pancreatic islet microfibers for enhanced immunoprotection. Biomaterials 2013;34:8122-30.

12. Joglekar MV, Joglekar VM, Hardikar AA. Expression of islet-specific microRNAs during human pancreatic development. Gene Expr Patterns. 2009;9:109-13.

13. Pandey AK, Agarwal P, Kaur K, Datta M, Biochemistry. MicroRNAs in diabetes: tiny players in big disease. Cell Physiol Biochem. 2009;23:221-32. 
14. Poy MN, Eliasson L, Krutzfeldt J, Kuwajima S, Ma X, Macdonald PE, Pfeffer S, Tuschl T, Rajewsky N, Rorsman P, Stoffel M. A pancreatic islet-specific microRNA regulates insulin secretion. Nature. 2004;432:226-30.

15. Poy MN, Hausser J, Trajkovski M, Braun M, Collins S, Rorsman P, Zavolan M, Stoffel M.. miR-375 maintains normal pancreatic a-and $\beta$-cell mass. Proc Natl Acad Sci. 2009;106:5813-8.

16. Li Y, Xu X, Liang Y, Liu S, Xiao H, Li F, Cheng H, Fu Z. miR-375 enhances palmitate-induced lipoapoptosis in insulin-secreting NIT-1 cells by repressing myotrophin (V1) protein expression. Int J Clin Exp Pathol. 2010;3:254.

17. Bartel DP. MicroRNAs: target recognition and regulatory functions. Cell. 2009;136:215-33.

18. Dumortier O, Hinault C, Gautier N, Patouraux S, Casamento V, Van Obberghen E. Maternal protein restriction leads to pancreatic failure in offspring: role of misexpressed microRNA-375. Diabetes. 2014;63:3416-27.

19. Wang Y, Liu J, Liu C, Naji A, Stoffers DAJD. MicroRNA-7 regulates the mTOR pathway and proliferation in adult pancreatic $\beta$-cells. 2013;62:887-95.

20. Latreille M, Hausser J, Stützer I, Zhang Q, Hastoy B, Gargani S, Kerr-Conte J, Pattou F, Zavolan M, Esguerra JL, Eliasson L. MicroRNA-7a regulates pancreatic $\beta$ cell function. J Clin Invest. 2014;124:2722-35.

21. Xu H, Guo S, Li W, Yu P. The circular RNA Cdr1as, via miR-7 and its targets, regulates insulin transcription and secretion in islet cells. Sci Rep. 2015;5:1-12.

22. Shantikumar S, Caporali A, Emanueli C. Role of microRNAs in diabetes and its cardiovascular complications. Cardiovasc. Res. 2012;93:583-93.

23. Heirani-Tabasi A, Toosi S, Mirahmadi M, Mishan MA, Bidkhori HR, Bahrami AR, Behravan J, NaderiMeshkin $\mathrm{H}$. Chemokine receptors expression in MSCs: comparative analysis in different sources and passages. J Tissue Eng Regen Med. 2017;14:605-15.

24. Eliasson L. The small RNA miR-375-a pancreatic islet abundant miRNA with multiple roles in endocrine beta cell function. Mol Cell Endocrinol. 2017;456:95-101.

25. Jafarian A, Taghikani M, Abroun S, Allahverdi A, Lamei M, Lakpour N, Soleimani M. The generation of insulin producing cells from human mesenchymal stem cells by MiR-375 and anti-MiR-9. PLoS One. 2015;10: 1-18.

26. Keller DM, McWeeney S, Arsenlis A, Drouin J, Wright CV, Wang H, Wollheim CB, White P, Kaestner KH, Goodman $\mathrm{RH}$. Characterization of pancreatic transcription factor $\mathrm{Pdx}-1$ binding sites using promoter microarray and serial analysis of chromatin occupancy. J BIOL CHEM. 2007;282:32084-92.

27. Rosero S, Bravo-Egana V, Jiang Z, Khuri S, Tsinoremas N, Klein D, Sabates E, Correa-Medina M, Ricordi C, Domínguez-Bendala J, Diez J. MicroRNA signature of the human developing pancreas. BMC genomics. 2010;11:509.

28. Daneshmandi S, Karimi MH, Pourfathollah AA. TGF- $\beta$ engineered mesenchymal stem cells (TGF$\beta /$ MSCs) for treatment of Type 1 diabetes (T1D) mice model. Int Immunopharmacol. 2017;44:191-6. 
29. Tian Y, Xu J, Du X, Fu X. The interplay between noncoding RNAs and insulin in diabetes. Cancer Lett. 2018;419:53-63.

30. Waselle L, Coppola T, Fukuda M, lezzi M, El-Amraoui A, Petit C, Regazzi R. Involvement of the Rab27 binding protein Slac2c/MyRIP in insulin exocytosis. Mol. Biol. Cell. 2003;14:4103-13.

31. Chandika P, Ko S-C, Oh G-W, Heo S-Y, Nguyen V-T, Jeon Y-J, Lee B, Jang CH, Kim G, Park WS, Chang W. Fish collagen/alginate/chitooligosaccharides integrated scaffold for skin tissue regeneration application. Int J Biol Macromol. 2015;81:504-13.

32. Karri VV, Kuppusamy G, Talluri SV, Mannemala SS, Kollipara R, Wadhwani AD, Mulukutla S, Raju KR, Malayandi R. Curcumin loaded chitosan nanoparticles impregnated into collagen-alginate scaffolds for diabetic wound healing. Int J Biol Macromol. 2016;93:1519-29.

33. Lee BR, Hwang JW, Choi YY, Wong SF, Hwang YH, Lee DY, Lee SH. In situ formation and collagenalginate composite encapsulation of pancreatic islet spheroids. Biomaterials. 2012;33:837-45.

34. Silva Al, de Matos AN, Brons IG, Mateus M. An overview on the development of a bio-artificial pancreas as a treatment of insulin-dependent diabetes mellitus. MED RES REV. 2006;26:181-222.

35. Nanji SA, Shapiro AJ, Obesity, Metabolism. Advances in pancreatic islet transplantation in humans. Diabetes Obes Metab. 2006;8:15-25.

36. Safley SA, Cui H, Cauffiel S, Tucker-Burden C, Weber CJ. Biocompatibility and immune acceptance of adult porcine islets transplanted intraperitoneally in diabetic NOD mice in calcium alginate poly-Llysine microcapsules versus barium alginate microcapsules without poly-L-lysine. J Diabetes Sci Technol. 2008; 2: 760-67.

37. Veiseh O, Doloff JC, Ma M, Vegas AJ, Tam HH, Bader AR, Li J, Langan E, Wyckoff J, Loo WS, Jhunjhunwala S. Size-and shape-dependent foreign body immune response to materials implanted in rodents and non-human primates. Nat. Mater. 2015;14:643-51.

38. Pisania A, Weir GC, O'neil JJ, Omer A, Tchipashvili V, Lei J, Colton CK, Bonner-Weir S. Quantitative analysis of cell composition and purity of human pancreatic islet preparations. Lab Invest. 2010;90:1661-75.

39. Beebe DJ, Mensing GA, Walker GM. Physics and applications of microfluidics in biology. ANNU REV BIOMED ENG. 2002;4:261-86.

40. El-Ali J, Sorger PK, Jensen KF. Cells on chips. Nature. 2006;442:403-11.

\section{Figures}



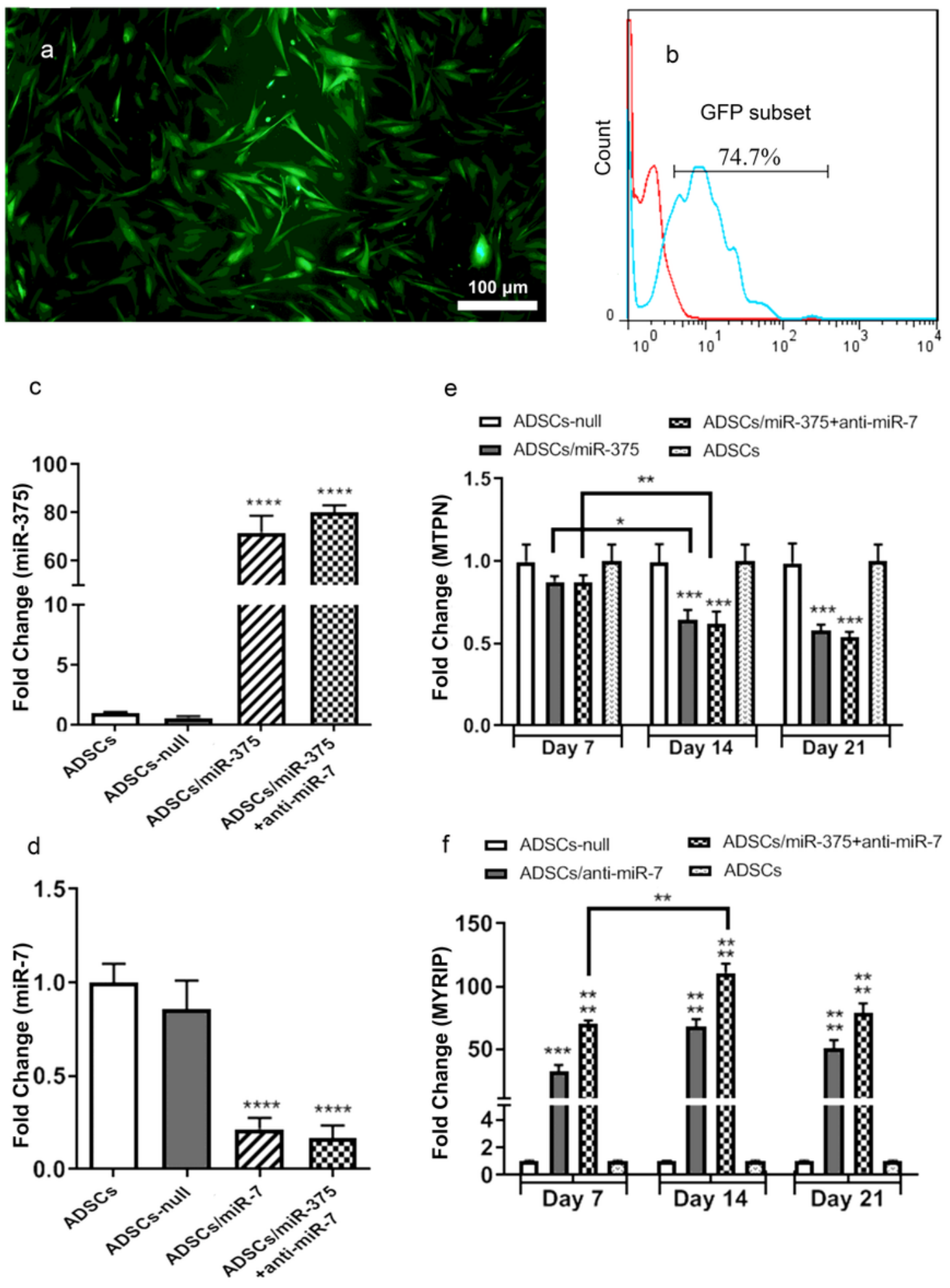

\section{Figure 1}

Adipose-derived stem cells purification and infection. (a) The results of miR-375 and anti-miR-7 transduction examined by fluorescent microscopy, scale bars are $100 \mu \mathrm{m}$ (b) The transduction efficiency of ADSCs was about 75\% in comparison to control ADSCs as determined by flow cytometry ( $c \& d$ ) Expression of miR-375 and miR-7 in test and control groups was measured by qRT-PCR on day 4 after transduction (e\& f) Detection of the expression level of target mRNAs, Mtpn, and Myrip, were analyzed at 
different days of differentiation into IPCs in test and control groups by qRT-PCR. All tests were performed in triplicate, and data were presented as mean $\pm S D$. * $P<0.05$.

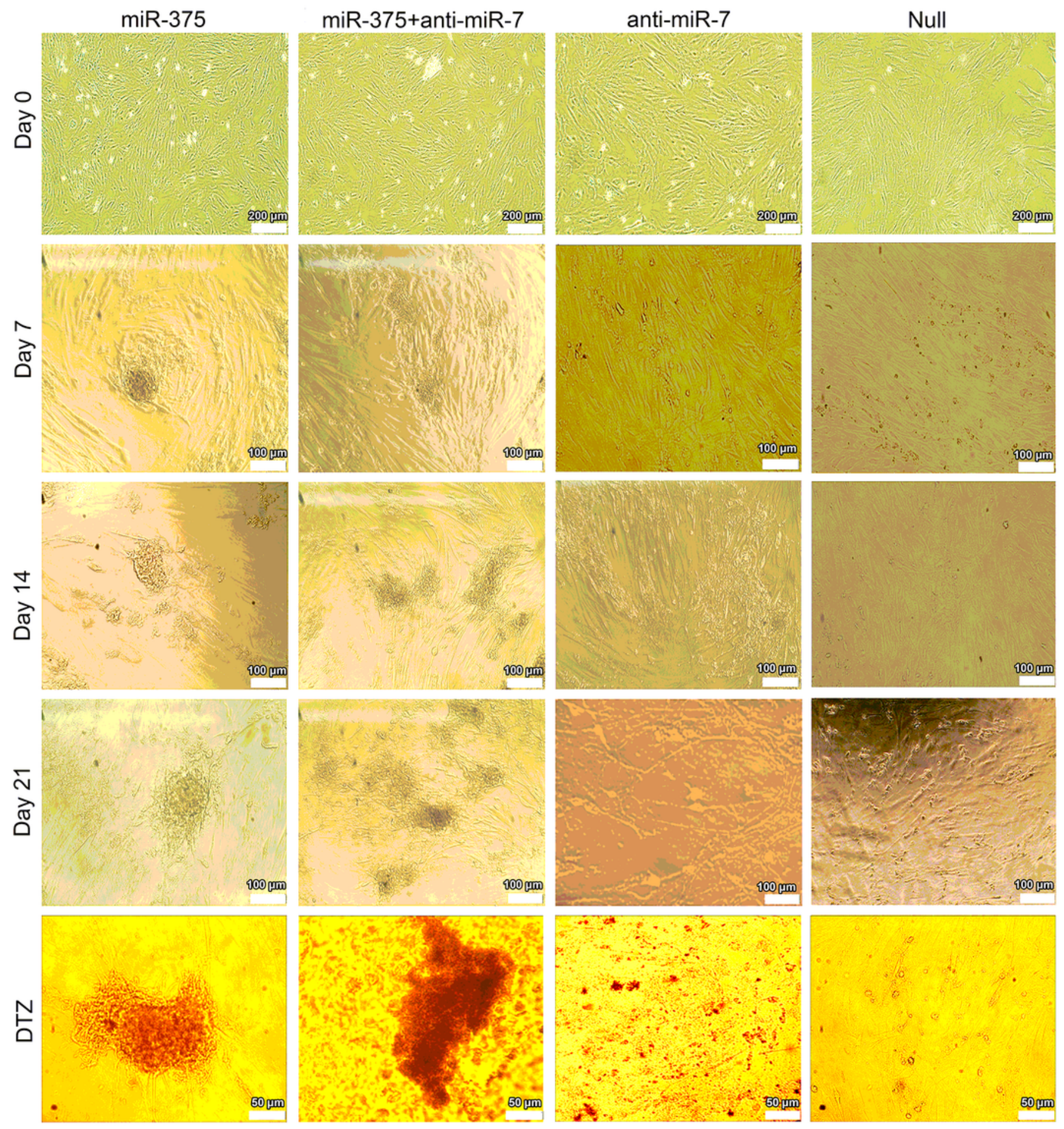

Figure 2

Morphological features of adipose-derived stem cells during differentiation (Dithizone staining). Spindle like cells (Day 0, scale bars are $200 \mu \mathrm{m}$ ) were differentiated into IPCs by inducing miR-375 and/or antimiR-7 transduction in 21 days. After 7 days of induction, the cells became aggregate, and some new islet- 
like clusters began to appear, and after 14 days, the number of matured aggregates increased, and at the

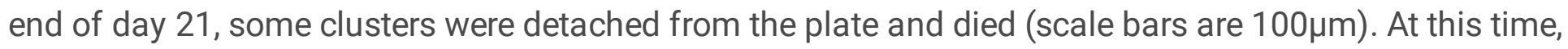
differentiated cells that were positive for DTZ staining appeared (scale bars are $50 \mu \mathrm{m}$ ).
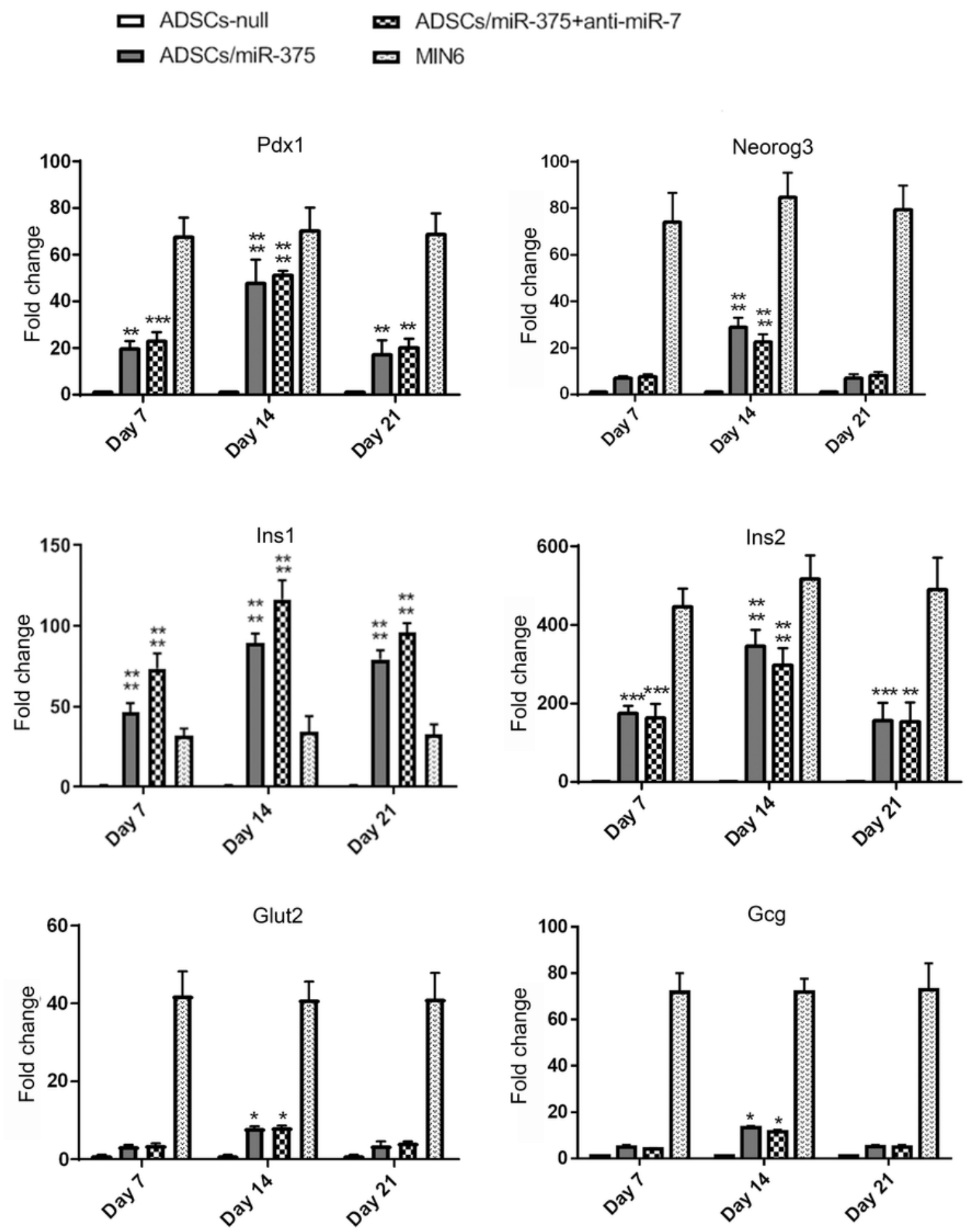

Figure 3

Expression of pancreatic endocrine genes in insulin producing cells derived from adipose-derived stem cells (QPCR). The expression levels of pancreatic transcription factors such as Pdx1 and Neurog3, 
endocrine markers: Ins1, Ins2, Gcg, and beta-cells specific gene like Glut2 were analysed at each stage of differentiation into IPCs. Gene transcripts of IPCs were compared with undifferentiated ADSCs null (negative control) and MIN-6 cell line (positive control). Relative levels of gene expression were normalized to mouse glyceraldehyde-3-phosphate dehydrogenase (GAPDH). Transcript value is shown in each graph as mean \pm SD. $* P<0.05$.

\section{a miR-375+ anti-miR-7}
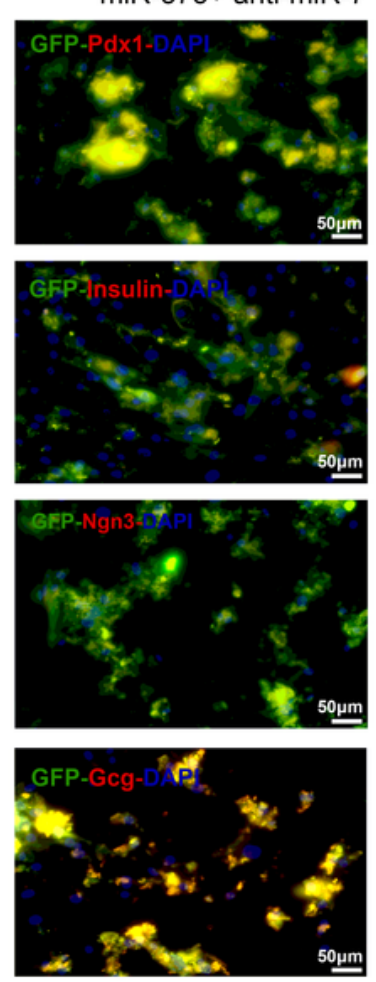

- MSCs null

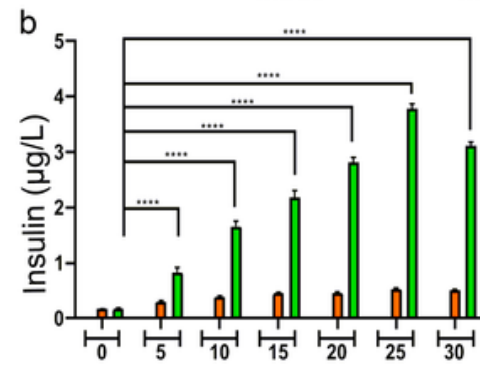

d Glucose Concentration (mM)

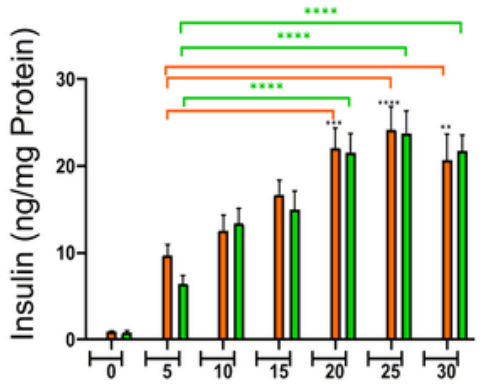

Glucose Concentration (mM)
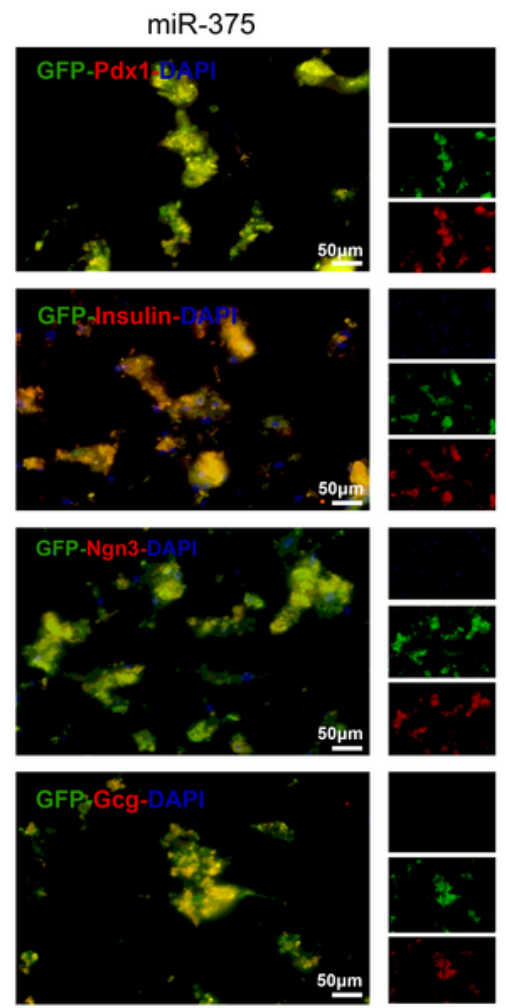

ㅁ MSCs ${ }^{\text {mir-375+anti-miR-7 }}$

C

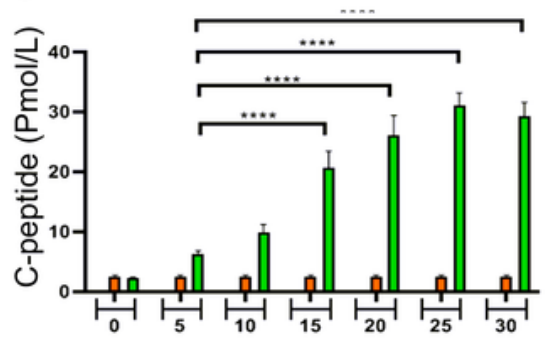

e

Glucose Concentration (mM)

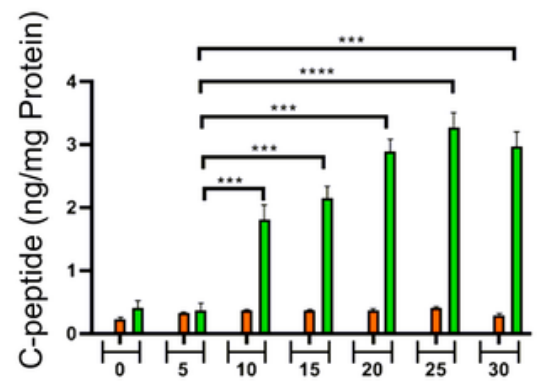

Glucose Concentration (mM)

Figure 4 
Immunocytochemical analysis and in vitro glucose response assay in derived IPCs (a) Immunofluorescence analysis detected nuclei localization of Pdx1, Neurog3 and cytoplasmic localization of Insulin, and Glucagon in differentiated IPCs by ADSCsmiR-375 and ADSCsmiR-375+anti-miR-7 on day 21. The staining of the nucleus (blue) was performed by DAPI (b) Insulin secreted in cultured media in response to various concentrations of glucose from 5 to $30 \mathrm{mmol}$; (c) C-peptide released in culture media; (d) Intracellular insulin content in each concentration of glucose that normalized with total cellular protein; (e) Intracellular C-peptide content in different concentrations of glucose that normalized with total cellular protein. Significant amounts of insulin and C-peptide were obtained in the ADSCsmiR-375+antimiR-7 group. The data are presented as mean $\pm S D$. * $P<0.05$. 

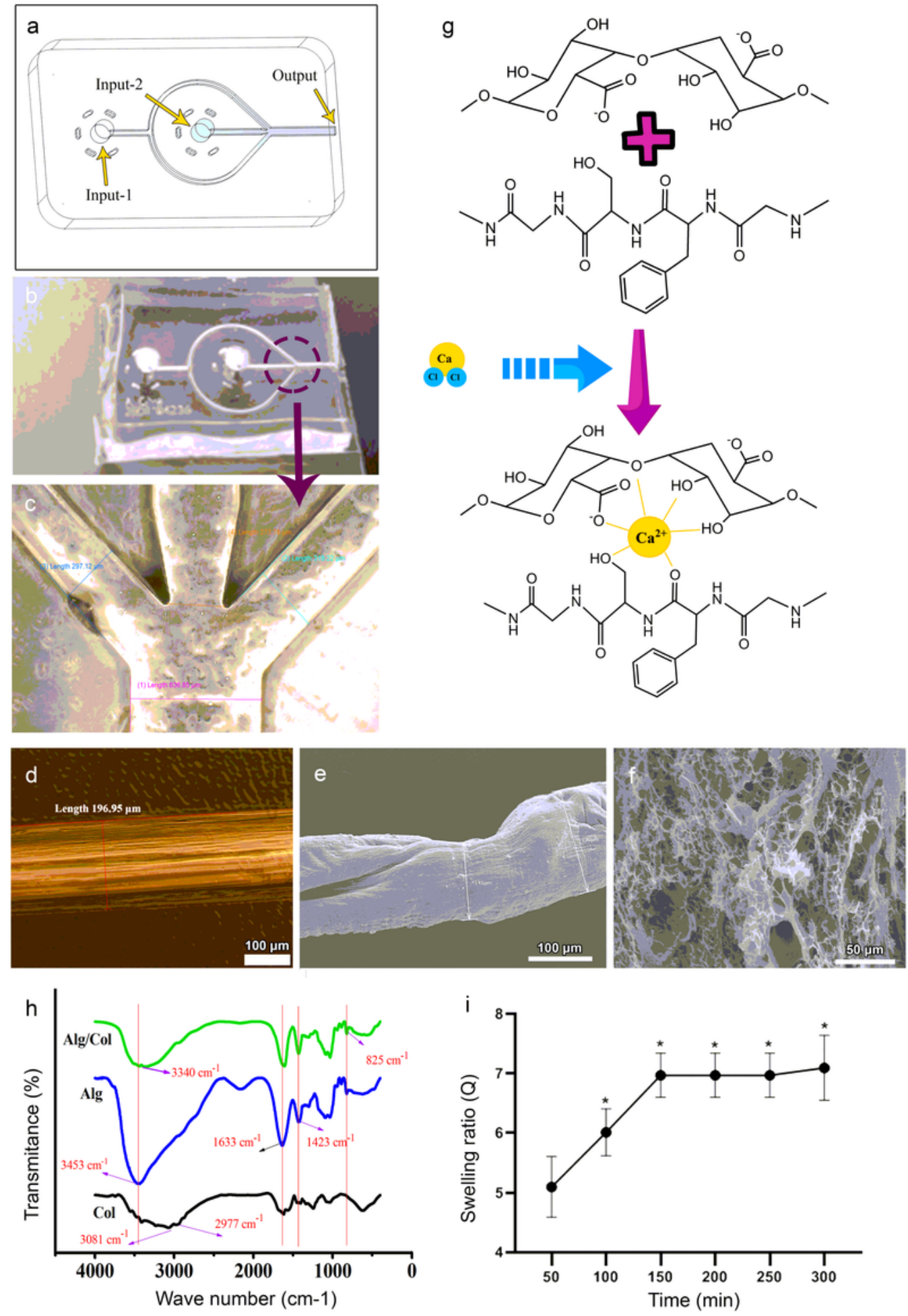

\section{Figure 5}

Fabrication of microfluidic device and characterization of microfibers fabricated using the microfluidic system (a) The schematic microfluidic chip (b) Microfluidic chip round micro-channels with various dimensions (c) Round micro-channels with various dimensions of the microfluidic chip (d) Optical image of Collagen-Alginate of fibers having equal diameter proportional to the size of the islets (e) SEM images of alginate fiber (f) Porous surface of fiber $(\mathrm{g})$ chemical structure of collagen-alginate in presence of 
cacl2 as cross linker (h) FTIR spectra of collagen-alginate (i) Swell ability ratio of Collagen-Alginate microfiber during 300 min immersed in media at $37 \circ \mathrm{C}$.

\section{Day 1}
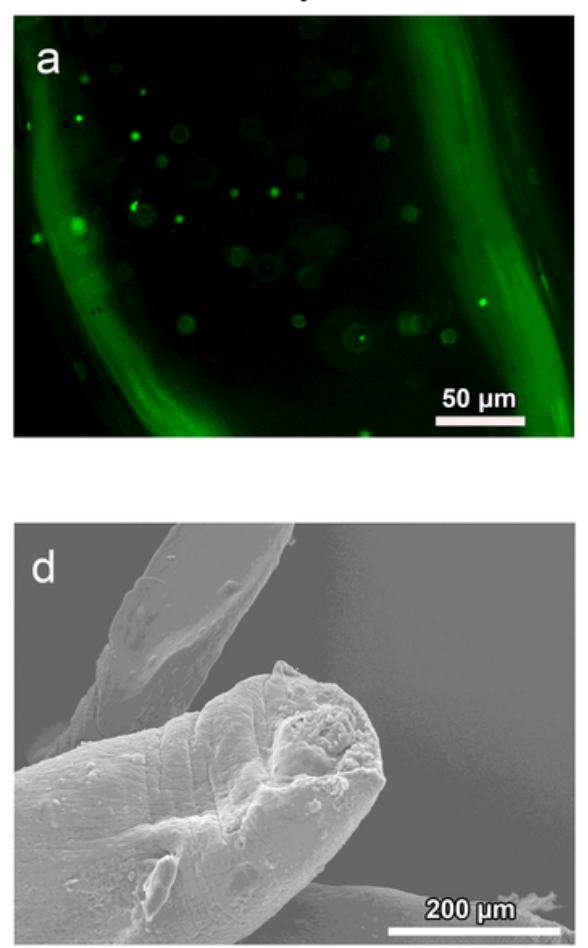

Day 7
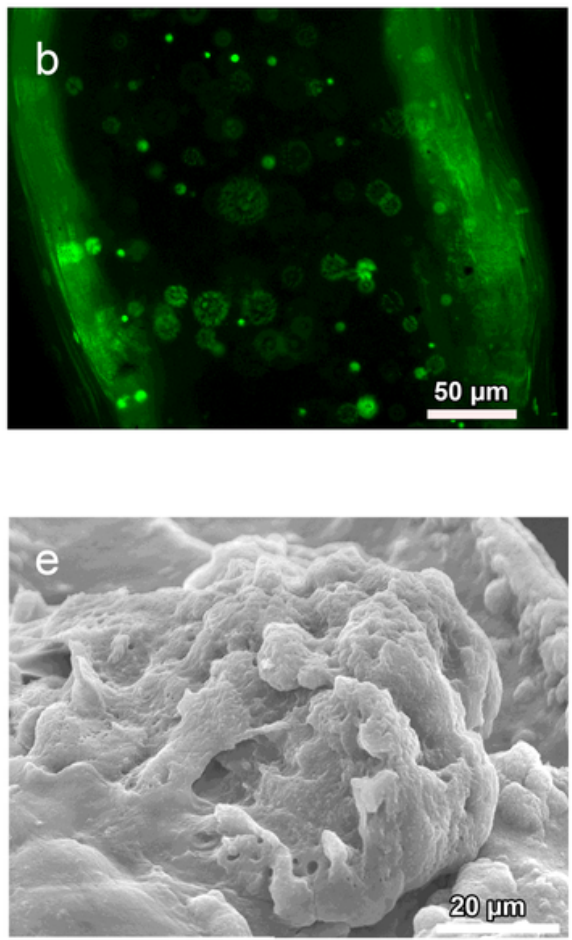
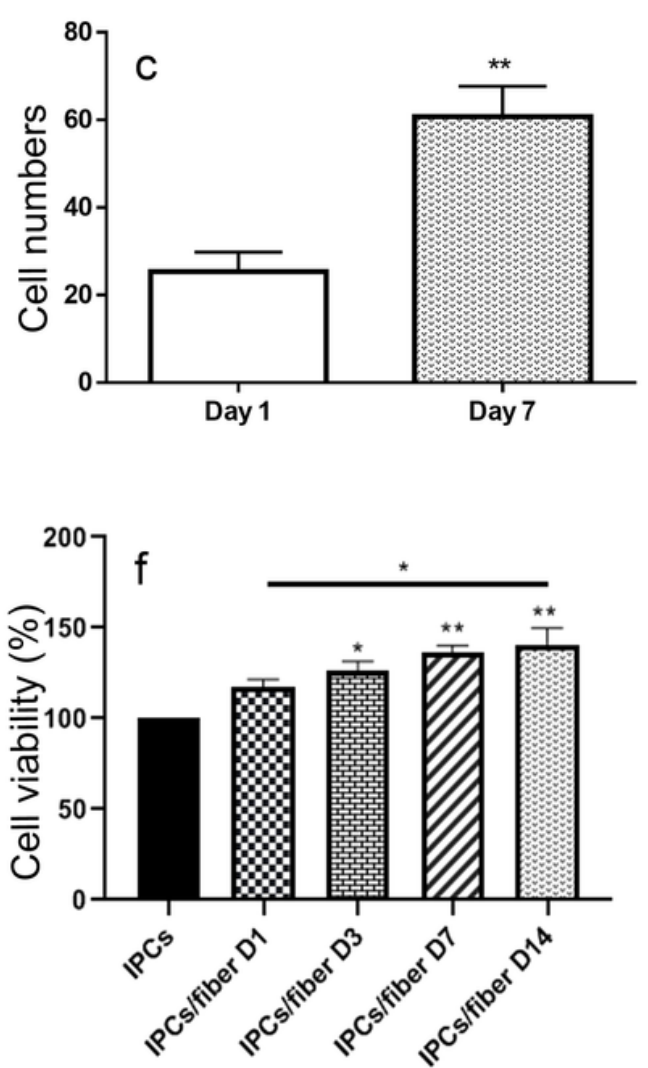

Figure 6

Viability and microscopic examination of the entrapped cells in microfibers (a) The results of live/dead staining after day 1 of encapsulation (b) after day 7 of encapsulation by fluorescent microscopy, scale bars are $50 \mu \mathrm{m}$ (c) comparison of live cells number between day 1 and 7 (d) Fiber cross-sectional surface with IPCs, scale bars is $200 \mu \mathrm{m}$ and, (e) Magnified cross-sectional surface with IPCs in fiber, scale bars is $20 \mu \mathrm{m}(\mathrm{f})$ Viability of collagen- alginate fiber-entrapped cells in vitro after days $1,3,7,14$. 
a
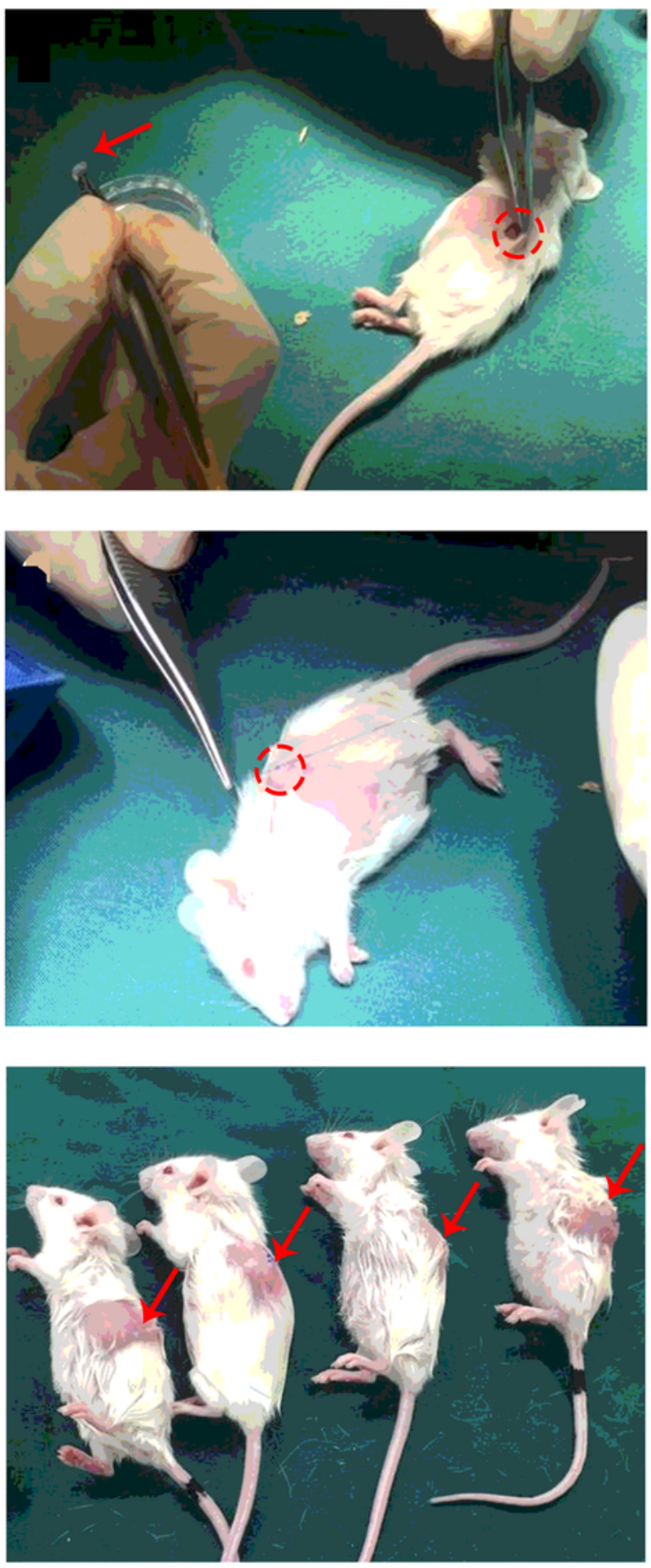

b
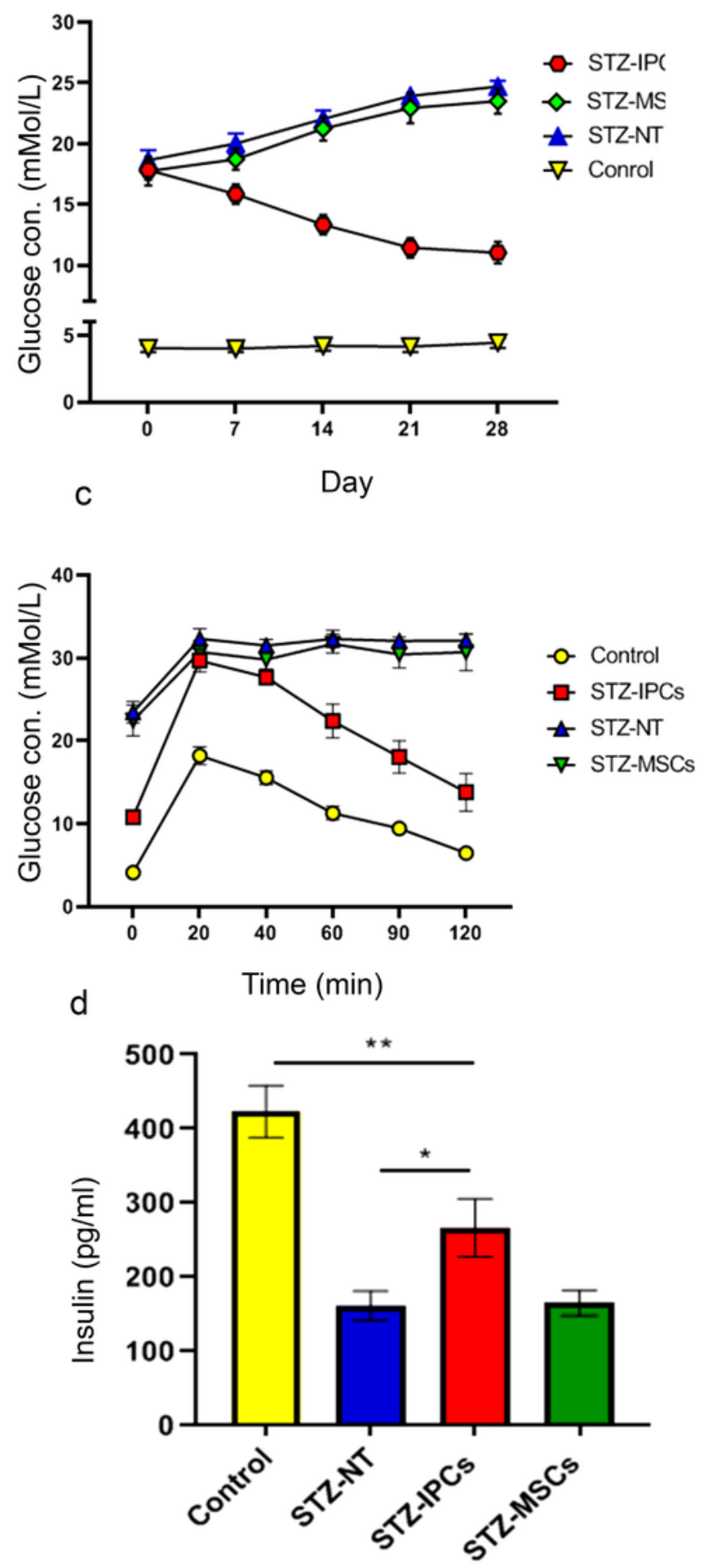

\section{Figure 7}

In vivo grafting of the cell clusters in diabetic mice (a) use of encapsulated IPCs for graft transplantation in diabetic mice (b) The non-fasting blood glucose level in STZ-induced diabetic BALB/c mice after transplantation of fiber-entrapped IPCs compare to fiber-entrapped ADSCs (c) diabetic mice, and nondiabetic mice during four weeks Fasting blood glucose levels of mice during I.P glucose tolerance test (GTT) during four weeks after transplantation and (d) serum insulin levels on day 35. Non-diabetic mice 
as Control, $n=5$, Diabetic mice without any treatment as NT-STZ, $n=5$, Treated diabetic mice with IPCs and MSCs as test groups, $\mathrm{n}=5$.

\section{Supplementary Files}

This is a list of supplementary files associated with this preprint. Click to download.

- graphicalabstract.jpg

- Additionalfile2.pdf

- Additionalfile1.pdf 